\title{
Job-related stress in psychiatric nurses in Japan caring for elderly patients with dementia
}

\author{
Hironori Yada $\cdot$ Hiroshi Abe $\cdot$ Xi Lu $\cdot$ \\ Yuko Wakizaki · Hisamitsu Omori · \\ Hisae Matsuo • Yasushi Ishida • Takahiko Katoh
}

Received: 8 July 2014/ Accepted: 10 September 2014/Published online: 7 October 2014

(c) The Japanese Society for Hygiene 2014

\begin{abstract}
Objectives We investigated the specificity and structures of job-related stress in psychiatric dementia nurses (PDNs) caring for elderly patients with serious behavioral and psychological symptoms of dementia who required substantial assistance with activities of daily living, in order to obtain fundamental knowledge toward providing mental health care for these nurses.

Methods Subjects were 244 nurses [63 PDNs and 181 other psychiatric nurses (OPNs)]

Results Analysis of covariance to examine the specificity of job-related stress in PDNs revealed physical workload and work environment to be more significant stressors, and irritability and anxiety to be more significant stress reactions in PDNs than in OPNs. An examination of PDNs' job-related stress structures established in a structural equation model with two stress reactions confirmed as specific outcomes for PDNs revealed a significant positive influence of work environment on irritability; utilization of
\end{abstract}

H. Yada $\cdot$ X. Lu · H. Omori · T. Katoh

Department of Public Health, Faculty of Life Sciences,

Kumamoto University, 1-1-1 Honjo, Kumamoto 860-8556,

Japan

H. Yada $(\bowtie)$

Department of Nursing, Kumamoto Health Science University,

325 Izumi, Kumamoto 861-5598, Japan

e-mail: yada@kumamoto-hsu.ac.jp

H. Abe - H. Matsuo - Y. Ishida

Department of Psychiatry, Faculty of Medicine, University of

Miyazaki, 5200 Kihara, Kiyotake, Miyazaki 889-1692, Japan

Y. Wakizaki

Former School of Nursing at Fukuoka, International University

of Health and Welfare, 1-7-4 Momochihama,

Fukuoka 814-0001, Japan techniques for anxiety and physical workload influenced both stress reactions.

Conclusions Our findings highlight the importance of reducing physical workload and environment and establishing a structure for nursing techniques in psychiatric dementia wards to improve the mental health of PDNs.

Keywords Behavioral and psychological symptoms of dementia - Mental health - Occupational health . Psychiatric nursing $\cdot$ Psychological stress

\section{Introduction}

In 2000, $17 \%$ of the Japanese population was aged 65 and over, and this figure is expected to rise to $28 \%$ by 2025 [1], indicating that Japan is the fastest-aging society in the world, with the fewest children [2]. People that aged over 65 are defined the elderly in Japan, this aging is also evident in medical care, with people aged 65 and over representing $40 \%$ of all patients [3]. As the age of patients increases, they become more vulnerable to physical illness [4] and are at increased risk of mental illnesses such as dementia [5, 6]. It is estimated that there will be 2.5 million people with dementia in Japan by 2015 , and 3.23 million by 2025 [7]. While the total number of patients in psychiatric wards has been trending downwards in recent years, the number of dementia patients entering psychiatric wards is increasing annually [3]. In 2011, there was a total of 307,000 inpatients in psychiatric wards; however, the number of dementia inpatients has risen by about 20,000 since 1996, reaching 53,000 in 2011 [8].

Psychiatric medical care wards for elderly dementia patients, referred to as psychiatric dementia wards, were established in 1996 as part of the medical treatment fee 
system in Japan for dementia patients receiving psychiatric care [9]. Psychiatric dementia wards were created to provide treatment for patients with advanced dementia and especially pronounced mental symptoms and behavioral abnormalities [10]. Symptoms of dementia are broken down into core symptoms, such as memory loss and disorientation, and behavioral and psychological symptoms of dementia (BPSD), which include delirium, aggression, and wandering [7]. BPSD may be a burden to psychiatric dementia ward staff providing specialized care for dementia. In a study on BPSD in 105 psychiatric dementia wards [11], the most frequent symptoms observed were wandering and resistance to care. Resistance to care is the most difficult symptom to deal with, as it often impedes nurses' work. Moreover, wandering is a risk factor for falls in dementia patients [12]. A study examining the rate of falls by type of facility found higher fall rates at geriatric psychiatric facilities than at geriatric rehabilitation facilities or nursing homes [13]. While over half of the patients in psychiatric wards have a medical problem [14], approximately $90 \%$ of dementia patients in psychiatric wards have physical complications that require medical treatment, and approximately $20 \%$ of them receive a physical check-up on a monthly basis, at least [15]. Over $80 \%$ of dementia patients need assistance with eating, toileting, bathing, and dressing [15].

Nurses in psychiatric medical care wards for elderly dementia patients (psychiatric dementia nurses: PDNs) not only deal with serious BPSD, but also provide a substantial amount of care for physical illness and activities of daily living (ADL). As a result, PDNs are overwhelmed by nursing care duties and likely sustain higher job-related stress from physical burden and mental fatigue than nurses in other psychiatric wards.

Job-related stress has major negative effects, not only on the mental health of psychiatric nurses, but also on healthcare services [16-19]. One example of these effects is physical abuse of elderly individuals [20]. In recent years, there have been incidents of abuse of dementia patients by PDNs, which may have occurred as a result of job-related stress [21]. Reducing job-related stress is therefore an urgent occupational health issue that could be targeted with PDN-specific mental health care.

In order to provide PDNs with mental health care, it is essential first to determine the characteristics and structures of their job-related stress. Various studies have examined the burden placed upon caregivers who provide dementia care and stress in nursing staff at senior facilities [22-27]. To our knowledge, however, no studies have been conducted on job-related stress in PDNs caring for patients who require substantial assistance in $\mathrm{ADL}$ and/or have severe BPSD.
In the present study, we compared job-related stress in PDNs and OPNs to determine whether there is a type of job-related stress specific to PDNs. We also attempted to determine the structures underlying this specific job-related stress to obtain fundamental knowledge regarding the provision of mental health care for PDNs.

\section{Materials and methods}

\section{Participants}

Three hundred eighty-five psychiatric nurses, including registered and assistant nurses, from six psychiatric hospitals in Prefecture A in Japan participated in the study. Anonymous self-administered questionnaires were sent to participants via mail between November 17 and December 21, 2009. Subjects were informed of the purpose of the study and assured that their privacy would be protected and their participation in the study would not result in unfair treatment. In order to prevent identification of individuals and leakage of personal information to others in the hospitals, anonymity was ensured by having each subject seal his or her completed questionnaire in an envelope provided in advance. A total of 302 nurses provided written consent to participate in the study. Of those, data from 244 were included in the analysis following the exclusion of incomplete questionnaires (valid response rate: $63.4 \%$ ). A total of 63 participants were PDNs and 181 were OPNs. PDNs of the present study are nurses in psychiatric wards of general hospitals. OPNs included psychiatric nurses who treated a wide area of acute and chronic mental diseases, alcohol dependence, physical complications, and adolescent mental diseases. In addition, a portion of the data from a previous study [28] was used in the present study in order to explore stress-related PDNs, although the aims of the two studies were different. The study protocol was approved by the ethics committee of Kumamoto University Graduate School of Life Sciences.

\section{Procedures}

The survey used in this study recorded basic characteristics such as age, job position, qualifications, experience working in other departments, and years of experience in psychiatry (basic attribute).

Continuous variables such as age and years of experience in psychiatry department were answered by single item checklists, and categorical variables such as Job position, qualification and experience working in other departments were answered by single item checklists. The categorical variables were dichotomized as follows: male (0), female (1); position as non-manager (0), manager (1); 
qualifications as registered nurse (0), assistant nurse (1), and experience working in other departments as yes $(0)$ or no (1). To assess job-related stress in psychiatric nurses, we used the psychiatric nurse job stressor scale (PNJSS) developed by Yada et al. [28] and the job stressor (JSS) and stress reaction (SRS) scales from the brief job stress questionnaire (BJSQ) developed by Shimomitsu et al. [29].

The PNJSS [28] was developed by standardizing 302 psychiatric nurses' job-related stressors in order to assess job-related stressors unique to psychiatric nurses. Each item is ranked by the respondent along a $100-\mathrm{mm}$ visual analogue scale (VAS), with $1 \mathrm{~mm}$ equal to 1 point. Scores ranged from 0 to $100(0=$ not at all, $100=$ yes $)$; higher scores indicate stronger job-related stressors. The PNJSS comprises a psychiatric nursing ability subscale (9 items), an attitude of patients subscale (6 items), an attitude toward nursing subscale (5 items), and a communication subscale ( 2 items). The reliability [Cronbach's $\alpha=0.675-0.869$, item-scale correlation $=0.265-0.570(P<0.01)$, and testretest correlation $=0.493-0.771(P<0.01)]$ and convergent $\quad(R=0.172-0.420 ; \quad P<0.01), \quad$ predictive $(R=$ $0.201-0.453)$ and factorial validity $\left(\chi^{2} / d f\right.$ ratio $=343.189 /$ 196 at $P<0.01$, goodness-of-fit index $=0.910$, adjusted goodness-of-fit index $=0.883, \quad$ comparative fit index $=0.924$ and root mean square error of approximation $=0.050$ ) have been verified for this study [28].

The BJSQ was developed by standardizing job-related stress in chemistry, industry, electricity, iron manufacture, electric power, sugar manufacture, life insurance, and small-scale enterprise workers [29]. This scale has been used in many recent job-related stress studies [30-38]. The JSS measures job-related stressors and assesses quantitative overload ( 3 items), mental demand ( 3 items), physical workload (1 item), job control (3 items), utilization of techniques ( 1 item), interpersonal relations ( 3 items), work environment (1 item), fit to the job (1 item), and reward of work (1 item). The SRS measures psychological and physical stress reactions. The psychological stress reaction scale assesses lack of vigour ( 3 items), irritability (3 items), fatigue ( 3 items), anxiety ( 3 items), and depressed mood ( 6 items), while physical stress reactions are assessed via a somatic symptoms subscale (11 items). Items are scored on a 4-point scale from 1 to $4(1=$ almost never, $4=$ most of the time). A higher score indicates a higher job relatedstressors and stress reactions. The reliability and validity of these scales have been verified [39].

\section{Statistical analysis}

The mean, standard deviation (SD) and number $(N)$ were calculated for basic attributes (age, gender, job position, qualifications, experience working in other departments and years of experience in psychiatry department).
Unpaired $t$ tests and analysis of covariance (ANCOVA) were performed for intergroup comparisons between continuous variables, and Chi-square tests were performed for intergroup comparisons between categorical variables. In conducting the ANCOVA, we confirmed significant intergroup distribution differences in basic attributes. To compare the basic attributes of PDNs and OPNs, unpaired $t$ tests were performed on age and years of experience in psychiatry, and Chi-square tests were performed on gender, position, qualifications, and experience working in other departments.

We set covariates as variables with significant difference for basic attributes, calculated the mean and standard error (SE) adjusted for PNJSS, JSS, and SRS subscale scores, and performed ANCOVA.

Following this, in conducting a structural equation model (SEM) in PDNs, we confirmed relationships between variables using sub-analyses. The National Institute for Occupational Safety and Health job stress model proposes that stress reactions are affected by job stressors [40], and previous studies have shown that age, rank, and experience affect job-related stress [41, 42]. In conducting the SEM to determine the effects of job-related stressors on stress reactions, stepwise multiple regression analysis adjusted for basic attributes was therefore performed for PDNs, with job-related stressors as explanatory (independent) variables and stress reactions as the objective (dependent) variable. In conducting the SEM to reveal correlations among the selected job-rerated stressors and stress reactions in stepwise multiple regression analysis, we calculated Pearson's correlation coefficients.

SEM was calculated to determine the structure of jobrelated stressors and stress reactions. $\chi^{2} / d f$ ratio $<2.0$ [43] and GFI $>0.90$, AGFI $>0.85$, CFI $>0.95$, RMSEA $<0.08$ [44] are the criteria of strong goodness-of-fit in SEM.

SPSS 21.0 for Windows (IBM, New York, USA) and Amos 21.0 (IBM, New York, USA) were used for all statistical analyses. Significance was set to $5 \%$ for all analyses.

\section{Results}

As shown in Table 1, a significant difference of ward was seen in age, gender, experience working in other departments, and years of experience in psychiatry. The means of age and experience in psychiatry, number of male participants, and experience working in other departments (Yes) for OPNs were significantly higher than for PDNs at levels of significance of $<1 \%$.

As shown in Table 2, we set age, gender, experience working in other departments, and years of experience in psychiatry (confirmed to differ between PDNs and OPNs) as covariates. PDNs had significantly higher scores than 
Table 1 Demographic variables of subjects

Age and years of experience in psychiatry department were compared by $t$ test. gender, job rank, qualifications and experience working in other departments were compared by $\chi^{2}$ test. magager was head nurse or chief nurse

\begin{tabular}{|c|c|c|c|c|c|c|c|}
\hline \multirow[t]{2}{*}{ Variables } & \multicolumn{2}{|c|}{$\begin{array}{l}\text { Psychiatric dementia } \\
\text { nurses }(N=63)\end{array}$} & \multicolumn{2}{|c|}{$\begin{array}{l}\text { Other psychiatric } \\
\text { nurses }(N=181)\end{array}$} & \multirow[t]{2}{*}{$t$ value } & \multirow[t]{2}{*}{$\chi^{2}$ value } & \multirow[t]{2}{*}{$P$ value } \\
\hline & $\begin{array}{l}\text { Mean or } \\
\text { Number }\end{array}$ & $\begin{array}{l}\text { SD or } \\
\%\end{array}$ & $\begin{array}{l}\text { Mean or } \\
\text { number }\end{array}$ & $\begin{array}{l}\text { SD or } \\
\%\end{array}$ & & & \\
\hline Age & 38.89 & 9.25 & 42.72 & 11.47 & -2.652 & & 0.009 \\
\hline \multicolumn{8}{|l|}{ Gender } \\
\hline Male (0) & 10 & $15.9 \%$ & 75 & $41.4 \%$ & & & \\
\hline Female (1) & 53 & 84.1 & 106 & 58.6 & & 13.453 & $<0.001$ \\
\hline \multicolumn{8}{|l|}{ Job position } \\
\hline Non-manager $(0)$ & 54 & $85.7 \%$ & 154 & $85.1 \%$ & & 0.015 & 0.903 \\
\hline Manager (1) & 9 & $14.3 \%$ & 27 & $14.9 \%$ & & & \\
\hline \multicolumn{8}{|l|}{ Qualifications } \\
\hline Registered nurse $(0)$ & 45 & $71.4 \%$ & 130 & $71.8 \%$ & & 0.004 & 0.952 \\
\hline Assistant nurse (1) & 18 & $28.6 \%$ & 51 & $28.2 \%$ & & & \\
\hline \multicolumn{8}{|c|}{ Experience working in other department } \\
\hline Yes $(0)$ & 33 & $52.4 \%$ & 136 & $75.1 \%$ & & 11.368 & 0.001 \\
\hline No (1) & 30 & $47.6 \%$ & 45 & $24.9 \%$ & & & \\
\hline $\begin{array}{l}\text { Years of experience in } \\
\text { psychiatry department }\end{array}$ & 10.32 & 7.96 & 13.80 & 10.74 & -2.717 & & 0.007 \\
\hline
\end{tabular}

OPNs on the subscales for physical workload, work environment (noise, illumination, temperature, ventilation etc.), irritability, and anxiety. Their differences exhibited levels of significance of $<5 \%$ in each case.

As shown in Table 3, we selected irritability and anxiety as objective variables by confirming significant levels in PDNs in Table 2. Significant positive effects were seen with PDNs in the physical workload and work environment subscales on the irritability subscale, and the physical workload and utilization of techniques subscales on the anxiety subscale. These effects exhibited levels of significance of $<5 \%$ in each case.

As shown in Table 4, a significant positive correlation was found between utilization of techniques and work environment, and irritability and anxiety subscales at a level of significance of $<5 \%$.

As shown in Fig. 1, a structure of job-related stress experienced by PDNs was confirmed by the SEM. Levels of significance shown in Tables 3 and 4 were assumed to be positive effects and correlations in the SEM. All positive job-related stressor effects on stress reactions exhibited at a level of significance of $<5 \%$. A correlation between utilization of techniques and work environment was found at a level of significance of $<10 \%$. A correlation between error variables for stress reactions was found at a level of significance of $<5 \%$. Fit indices of the proposed model were $\chi^{2} / d f(3.370 / 4, P=0.498)$ ratio $=0.842$; goodnessof-fit index $(\mathrm{GFI})=0.979$; adjusted goodness-of-fit index $(\mathrm{AGFI})=0.922 ;$ comparative fit index $(\mathrm{CFI})=1.000$; root mean square error of approximation (RMSEA)
$<0.001$; Akaike Information Criterion $(\mathrm{AIC})=25.37$. The SEM suggested that the fitness of the model is at an acceptable level. The model reported greater irritability was affected by work environment and physical workload, and greater anxiety was affected by physical workload and utilization of techniques. Knowledge of this model suggested the necessity for reducing job stressors as work environment, physical workload and utilization of techniques for PDNs.

\section{Discussion}

We investigated the specificity of job-related stress in PDNs in order to obtain fundamental knowledge in order to provide them with mental health care in the future. In comparison with previous studies [22-27], our findings were similar as nurses with dementia care had high stress levels [25], and stress with dementia care were related physical and emotional demands and workload [22]. However, a specific stress which has not been reported by previous studies [22-27] was job-related stressors as work environment (noise, illumination, temperature and ventilation, etc.) and utilization of techniques, and stress reaction as irritability and anxiety. The following is a discussion of our findings.

As shown in Table 1, there is also a large bias in the basic attributes such as age, gender and experience. Age, gender [42], and length of service [45] are known to affect occupational stress. Thus, we confirmed these factors as 
Table 2 Ward differences for each stress subscale mean scores

\begin{tabular}{lllll}
\hline Subscale & $\begin{array}{l}\text { Psychiatric } \\
\text { dementia } \\
\text { nurses } \\
(n=63)\end{array}$ & $\begin{array}{l}\text { Other } \\
\text { psychiatric } \\
\text { nurses } \\
(n=181)\end{array}$ & $F$ value & $P$ value \\
& & & \\
\hline PNJSS & $51.70(2.24)$ & $52.13(1.27)$ & 0.027 & 0.870 \\
$\begin{array}{l}\text { Psychiatric } \\
\text { nursing }\end{array}$ & & & & \\
$\quad$ ability & $50.94(2.52)$ & $45.64(1.43)$ & 3.116 & 0.076 \\
Attitude of & & & & \\
$\quad$ patients & $72.47(2.11)$ & $68.84(1.20)$ & 2.125 & 0.146 \\
Attitude toward \\
$\quad$ nursing
\end{tabular}

Differences in mean scores (standard error) for each scale were analyzed by analysis of covariance adjusted for age, gender, experience working in other departments and years of experience in psychiatry department

appropriate covariates for comparing job-related stress in Table 2.

The effect of work environment on irritability levels may be a function of the noise, foul odours and temperature setting on psychiatric dementia wards (Table 3; Fig. 1). Care managers $(\mathrm{CM})$ providing geriatric care felt that shouting was one of the most intolerable BPSD to deal with at work, and filthy behavior was one of the most frequently occurring BPSD in patients on psychiatric dementia wards [11]. When shouting is seen as noise, it may cause discomfort [46], and patients shouting on psychiatric dementia
Table 3 The effects of job stressors on stress responses of PDNs

\begin{tabular}{|c|c|c|c|c|c|c|}
\hline \multirow{3}{*}{$\begin{array}{l}\text { Selected } \\
\text { explanatory }\end{array}$} & \multicolumn{6}{|c|}{ Objective variable } \\
\hline & \multicolumn{3}{|c|}{ Irritability } & \multicolumn{3}{|c|}{ Anxiety } \\
\hline & $\beta$ & $t$ value & $P$ value & $\beta$ & $t$ value & $P$ value \\
\hline $\begin{array}{l}\text { Physical } \\
\text { workload }\end{array}$ & 0.288 & 2.584 & 0.012 & 0.310 & 2.800 & 0.007 \\
\hline $\begin{array}{l}\text { Utilization of } \\
\text { techniques }\end{array}$ & - & - & - & 0.228 & 2.068 & 0.043 \\
\hline $\begin{array}{l}\text { Work } \\
\text { environment }\end{array}$ & 0.391 & 3.500 & 0.001 & & & \\
\hline$R$ & \multicolumn{3}{|l|}{0.523} & \multicolumn{3}{|l|}{0.542} \\
\hline$R^{2}$ & \multicolumn{3}{|l|}{0.274} & \multicolumn{3}{|l|}{0.293} \\
\hline Adjusted $R^{2}$ & \multicolumn{3}{|l|}{0.250} & \multicolumn{3}{|l|}{0.257} \\
\hline$F$ value & \multicolumn{3}{|l|}{11.310} & \multicolumn{3}{|c|}{8.161} \\
\hline$P$ value & \multicolumn{3}{|c|}{$P<0.001$} & \multicolumn{3}{|c|}{$P<0.001$} \\
\hline
\end{tabular}

$\beta$ Standardized coefficient $\beta$; multiple regression analysis was adjusted for age, job position, qualifications, experience working in other departments, and years of experience in psychiatry departments

Table 4 Pearson's correlation coefficients among job-related stressors of PDNs

\begin{tabular}{lllllll}
\hline Explanatory variables & 1 & 2 & 3 & 4 & 5 \\
\hline $1 \quad$ Physical workload & 1 & - & - & & \\
2 & Utilization of & 0.114 & 1 & - & & \\
$\quad$ techniques & & & & & \\
$3 \quad$ Work environment & 0.186 & $0.256^{*}$ & 1 & & \\
$4 \quad$ Irritability & $0.354 * *$ & 0.189 & $0.439 * *$ & 1 & \\
$5 \quad$ Anxiety & $0.366^{* *}$ & $0.277 *$ & 0.008 & $0.374 * *$ & 1 \\
\hline$* P<0.05 ; * P<0.01$ & & & & &
\end{tabular}

wards may thus be expected to elicit irritability in PDNs. One of the most frequently occurring BPSD, filthy behavior can include dirtying the area with urine or faeces, and may result in foul odours. A field survey of staff working in acute wards regarding odours in wards found that the smell of urine and faeces was considered the most unpleasant odour; nurses were more bothered by those smells than were other ward staff [47]. Filthy behavior is the most frequently occurring BPSD in psychiatric dementia wards patients; therefore, PDNs may suffer more odour-related stress than nurses on other wards, which may affect their irritability level. In the environment that the elderly thermoregulation is often difficult, previous studies have showed a situation that can not be a comfortable temperature setting for psychiatric nurses are doing nursing work [48]; PDNs with caring elderly patients were expected greater irritability.

Although utilization of techniques was not a stressor that was highly specific to PDNs, it had a significant influence 
Fig. 1 The job-related stress structure of nurses in psychiatric ward for the geriatric patient with dementia

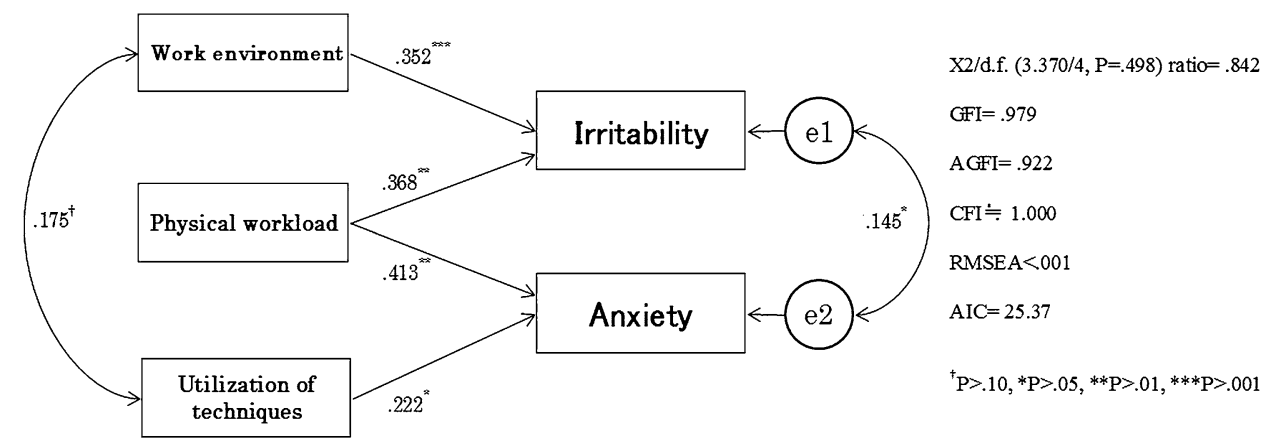

on anxiety (Table 3; Fig. 1). A survey on coexisting physical illnesses in geriatric dementia patients on psychiatric wards found a high prevalence of serious physical complications requiring diagnosis and treatment by specialists of other departments [49]. The psychiatric dementia wards that are the focus of the present study are not psychiatric wards in general hospitals. Similar to nurses in nursing homes [50], in single psychiatric hospitals, there is no department related to physical illnesses such as internal medicine or surgery. As a result, even if PDNs have knowledge and skills for managing physical illness, they may feel that they cannot provide adequate physical care. Underuse of knowledge and skills is one factor that can cause stress [51]. Considering the subjects in the present study, utilization of techniques is likely to influence anxiety.

Although there is only a significant trend between work environment and utilization of techniques (Fig. 1), a previous study showed an association between work environment and worker abilities [52]. PDNs may feel an inadequate exercise for skill on poor work environment, it is therefore debatable whether the path between work environment and utilization of techniques can be dismissed. Dismissing the path raises the Akaike Information Criterion (AIC) fit index that shows stronger goodness-offit with lower values [44] from 25.37 to 27.56, suggesting that it is more appropriate to keep the path between work environment and utilization of techniques.

Most inpatients at psychiatric dementia wards require care for ADL and instrumental ADL [15]. As a result, PDNs may be expected to suffer a much stronger physical burden in their work than OPNs. When PDNs continue to strain themselves physically in the course of their nursing duties, they may experience increased anxiety over their health in the future, with thoughts such as "Will I be able to continue nursing without suffering injury?" This anxiety may result in rushing; moreover, the physical burden may cause irritability.

As a limitation of this study, this study was a crosssectional study with 244 psychiatric nurses (63 PDNs and
181 OPNs) in Prefecture A as participants. Sampling bias and small sample size may have resulted in selection bias. There is also a large bias in the basic attributes such as age, gender and experience and environments among hospitals between PDNs and OPNs. In addition, the JSS items used are quite generalized, and cannot be used to identify specific stressors that affect the stress reaction in PDNs. In future studies, the sample size should be increased, and be necessary a research by adjusting the basic characteristics. Then, a scale should be used that can analyse the stressors thought to be specific to PDNs as shown in the present study in detail.

As consideration of mental health care for PDNs, the routine requirements of a psychiatric dementia ward can be expected to produce a significant physical workload for staff. There is a need for qualitative research to use interviews to uncover information about which tasks PDNs find physically demanding. To our knowledge, no studies have been conducted on the influence of odour, noise and temperature in psychiatric dementia wards. It may therefore be necessary to investigate and interview stress related to odour and noise, and the stressors with physical effects on psychiatric dementia wards. Finally, it is reasonable to conclude that there is a need to create a system to enable prompt response to the physical ailments of patients on psychiatric wards in order to protect their lives. Such a system may also lead to a reduction in stress for PDNs.

Acknowledgments We thank the doctors (Hiroshi Taniguchi, Hiroyuki Hashiguchi, Izumi Wakimoto, Jyungo Nakamura, Ryoei Miyoshi, Shigeki Kurayama, Syouhei Makita, Yoshio Mitsuyama, and Youko Tsuyama) and nurses in the psychiatric departments of the study hospitals for their cooperation with our research.

Conflict of interest None.

\section{References}

1. Nakamura M, Wada R. Setting social policies for Japan's declining birthrate and growing elderly population. NRI Papers. 2001;32:1-19. 
2. http://www.un.org/en/development/desa/population/publications/ pdf/ageing/2012PopAgeingandDev_WallChart.pdf Accessed 23 Aug 2013

3. Tanioka T, Kataoka M, Yasuhara Y, Miyagawa M, Ueta I. The role of nurse administrators and managers in quality psychiatric care. J Med Invest. 2011;58:1-10.

4. Burgess L, Page S. Educating nursing staff involved in the provision of dementia care. Nurs Times. 2003;46:34-7.

5. Dodge HH, Buracchio TJ, Fisher GG., Kiyohara Y, Meguro K, Tanizaki Y, et al. Trends in the prevalence of dementia in Japan. Int J Alzheimers Dis. doi: 10.1155/2012/956354 [Epub: 2012.10.3].

6. Meguro K, Tanaka N, Kasai M, Nakamura K, Ishikawa H, Nakatsuka M, et al. Prevalence of dementia and dementing diseases in the old-old population in Japan: the Kurihara Project. Implications for long-term care insurance data. Psychogeriatrics. 2012;12:226-34.

7. Mori T, Ueno S. Support provided to dementia patients by caregivers and the community. JMAJ. 2011;54:301-4.

8. http://www.mhlw.go.jp/kokoro/speciality/data.html Accessed 26 Aug 2013

9. Hamano T, Miyamoto Y, Ito H. A nationwide survey of trends in prospective payment system for psychiatric inpatient services. Nihon Koshu Eisei Zasshi. 2005;52:169-75 (Article in Japanese).

10. http://www.mhlw.go.jp/shingi/2009/11/dl/s1111-5a.pdf Accessed 26 Aug 2014

11. Maeda K, Ozaki T, Kawamata T. Survey for management of BPSD in care managers and special psychiatric wards for people with severe dementia. Seishin Shinkeigaku Zasshi. 2013;115:41-8 (Article in Japanese).

12. Rubenstein LZ, Josephson KR. Falls and their prevention in elderly people: what does the evidence show? Med Clin North Am. 2006;90:807-24.

13. Nyberg L, Gustafson Y, Janson A, Sandman PO, Eriksson S. Incidence of falls in three different types of geriatric care. A Swedish prospective study. Scand J Soc Med. 1997;25:8-13.

14. Fogel BS. A psychiatric unit becomes a psychiatric-medical unit: administrative and clinical implications. Gen Hosp Psychiatry. 1985;7:26-35.

15. http://www.mhlw.go.jp/stf/shingi/2r9852000000xcat-att/2r98520 00000xcgs.pdf Accessed 26 Aug 2013

16. Carson J, Fagin L. Stress in mental health professionals: a cause for concern or an inevitable part of the job? Int J Soc Psychiatry. 1996;42:79-81.

17. Dawkins JE, Depp FC, Selzer NE. Stress \& the psychiatric nurse. J Psychosoc Nurs Ment Health Serv. 1985;23:8-15.

18. Melchior ME, van den Berg AA, Halfens R, Huyer Abu-Saad H, Philipsen H, Gassman P. Burnout and the work environment of nurses in psychiatric long-stay care settings. Soc Psychiatry Psychiatr Epidemiol. 1997;1997(32):158-64.

19. Robinson JR, Clements K, Land C. Workplace stress among psychiatric nurses. Prevalence, distribution, correlates, \& predictors. J Psychosoc Nurs Ment Health Serv. 2003;41:32-41.

20. Schiamberg LB, Barboza GG, Oehmke J, Zhang Z, Griffore RJ, Weatherill RP, et al. Elder abuse in nursing homes: an ecological perspective. J Elder Abuse Negl. 2011;23:190-211.

21. Saito M, Shirahama T. A case of patients' abuse in a hospital for dementia care. Nippon Ronen Igakkai Zasshi. 2008;19:577-85 (Article in Japanese).

22. Eley R, Hegney D, Buikstra E, Fallon T, Plank A, Parker V. Aged care nursing in Queensland-the nurses' view. J Clin Nurs. 2007;16:860-72.

23. Hasson H, Arnetz JE. Nursing staff competence, work strain, stress and satisfaction in elderly care: a comparison of homebased care and nursing homes. J Clin Nurs. 2008;17:468-81.

24. Huang SS, Lee MC, Liao YC, Wang WF, Lai TJ. Caregiver burden associated with behavioral and psychological symptoms of dementia (BPSD) in Taiwanese elderly. Arch Gerontol Geriatr. 2012;55:55-9.

25. Josefsson K, Sonde L, Winblad B. Robins Wahlin TB. Work situation of registered nurses in municipal elderly care in Sweden: a questionnaire survey. Int J Nurs Stud. 2007;44:71-82.

26. Rodney V. Nurse stress associated with aggression in people with dementia: its relationship to hardiness, cognitive appraisal and coping. J Adv Nurs. 2000;31:172-80.

27. Tanji H, Ootsuki M, Matsui M, Maruyama M, Nemoto M, Tomita N, et al. Dementia caregivers' burdens and use of public services. Geriatr Gerontol Int. 2005;5:94-8.

28. Yada H, Abe H, Funakoshi Y, Omori H, Matsuo H, Ishida Y, et al. Development of the psychiatric nurse job stressor scale (PNJSS). Psychiatry Clin Neurosci. 2011;65:567-75.

29. Shimomitsu T, Yokoyama K, Ohono H, Maruta T, Tanigawa T. Manual of the Brief Job Stress Questionnaire. In: Reports on the study of job stress and its effects on health in the workplace: The research grant for the prevention of work-related diseases from the Japan Ministry of Labour. Tokyo: The Ministry of Labor, 2000 (in Japanese).

30. Harada H, Suwazono Y, Sakata K, Okubo Y, Oishi M, Uetani M, et al. Three-shift system increases job-related stress in Japanese workers. J Occup Health. 2005;47:397-404.

31. Kawada T, Otsuka T. Relationship between job stress, occupational position and job satisfaction using a brief job stress questionnaire (BJSQ). Work. 2011;40:393-9.

32. Kawakami N, Takao S, Kobayashi Y, Tsutsumi A. Effects of web-based supervisor training on job stressors and psychological distress among workers: a workplace-based randomized controlled trial. J Occup Health. 2006;48:28-34.

33. Kawano Y. Association of job-related stress factors with psychological and somatic symptoms among Japanese hospital nurses: effect of departmental environment in acute care hospitals. J Occup Health. 2008;50:79-85.

34. Mineyama S, Tsutsumi A, Takao S, Nishiuchi K, Kawakami N. Supervisors' attitudes and skills for active listening with regard to working conditions and psychological stress reactions among subordinate workers. J Occup Health. 2007;49:81-7.

35. Muto S, Muto T, Seo A, Yoshida T, Taoda K, Watanabe M. Job stressors and job stress among teachers engaged in nursing activity. Ind Health. 2007;45:44-8.

36. Tahara H, Yamada T, Nagafuchi K, Shirakawa C, Suzuki K, Mafune K, et al. Development of a work a work improvement checklist for occupational mental health focused on requests from workers. J Occup Health. 2009;51:340-8.

37. Umehara K, Ohya Y, Kawakami N, Tsutsumi A, Fujimura M. Association of work-related factors with psychosocial job stressors and psychosomatic symptoms among Japanese pediatricians. J Occup Health. 2007;49:467-81.

38. Urakawa K, Yokoyama K, Itoh H. Sense of coherence is associated with reduced psychological responses to job stressors among Japanese factory workers. BMC Res Notes. 2012;5:247. doi:10.1186/1756-0500-5-247.

39. Shimomitsu T, Haratani T, Iwata N, Yokoyama K, Ono Y, Tanigawa $\mathrm{T}$, et al. Development of a novel brief job stress questionnaire. Singapore, 26th International Congress on Occupational Health Abstract, 2000.

40. Hurrell JJ, McLaney MA. Exposure to job stress-a new psychometric instrument. Scand J Work Environ Health. 1988;14: 27-8.

41. Fisher MH. Factors influencing stress, burnout, and retention of secondary teachers. Current Issues in Education. 2011;14: $1-37$.

42. Sakai Y, Akiyama T, Miyake Y, Kawamura Y, Tsuda H, Kurabayashi L, et al. Temperament and job stress in Japanese company employees. J Affect Disord. 2005;85:101-12. 
43. Marsh HW, Balla J. Goodness of fit in confirmatory factor analysis: the effects of sample size and model parsimony. Qual Quant. 1994;28:185-217.

44. Schermelleh-Engell K, Moosbrugger $\mathrm{H}$, Muller H. Evaluating the fit of structural equation models: tests of significance and descriptive goodness-of-fit measures. Methods of Psychol Res Online. 2003;8:23-74.

45. Mohsen AH, Marzieh K, Negin MA. Nurses' perception of occupational stress and its influencing factors: a qualitative study. Iran J Nurs Midwifery Res. 2012;17:352-9.

46. Stansfeld SA, Matheson MP. Noise pollution: non-auditory effects on health. Br Med Bull. 2003;68:243-57.

47. Itakura T, Mitsuda M, Inagaki T. Questionnaire on nurse' feeling for hospital odors. J. Japan Assoc Odor Environ. 2006;37:437-48 (Article in Japanese).
48. Yada H, Abe H, Omori H, Ishida Y, Katoh T. Stressor among nurses in a psychiatric department: Comparison between acute and recuperation wards. J UOEH. 2009;31:293-303 (Article in Japanese).

49. Ukai K, Mizuno Y. Physical complications for elderly inpatients with senile dementia in the Imaise Branch of Ichinomiya City Hospital. Psychogeriatrics. 2010;9:167-72.

50. Matsuda T, Nagahata T, Ueno M, Gora J. Emotions of nurses caring for the elderly with dementia (in Japanese). J School Nurs Osaka Prefect Univ. 2006;12:85-91 (Article in Japanese).

51. Josefsson K. Registered nurses' health in community elderly care in Sweden. Int Nurs Rev. 2012;59:409-15.

52. Tengland PA. The concept of work ability. J Occup Rehabil. 2011;21:275-85. 